\title{
CARTA A UNA JOVEN FILÓLOGA
}

\author{
ANTONIO RAMÍREZ DE VERGER \\ Universidad de Huelva \\ rdverger@uhu.es \\ ORCID: 0000-0001-9803-3393
}

\section{RESUMEN}

Algunas reflexiones sobre la Filología Clásica: pasado, presente y futuro.

PALABRAS CLAVE: Filología, Filología Clásica.

\section{LETTER TO A YOUNG SCHOLAR}

\section{ABSTRACT}

Some thoughts on Classical Philology: past, present and future.

KEYWORDS: Philology, Classical Philology.

A finales de junio pasado recibí en la Universidad de Huelva una carta de una alumna recién graduada en la doble titulación de Clásicas e Hispánicas. Me reservo el nombre de la Universidad donde se había graduado. Me conocía de haber leído en la página web de la UHU mi lección inaugural del curso 2013-14, titulada Cuentos de un filólogo. ${ }^{1}$ Me decía que se sentía insatisfecha por la educación académica que había recibido en Primaria, en Secundaria y en la Universidad. Se sentía insegura y angustiada por su porvenir profesional, que deseaba encauzar hacia la docencia y la investigación, si fuera ello posible. Me rogaba que la aconsejara sobre el camino que debía seguir para aspirar a ser una buena profesional.

Tras rehacerme de mi sorpresa inicial, dejé pasar unos días, aunque no dejaba de dar vueltas en mi cabeza sobre si debía contestarle y, si fuera así, sobre cuál sería el tenor de la misiva. Por fin, a finales de julio y en un ambiente sereno y placentero, como el que se respira en Las Cuevas, una cerca de la Dehesilla de las Monjas, lugar próximo a Barcarrota (Badajoz), me atreví a responder a la joven filóloga.

Para empezar, le decía, no te vendría mal hacer una breve autoevaluación sobre tus competencias profesionales. Pregúntate a ti misma si eres capaz de leer con cierta soltura textos originales en griego, latín y español (de cualquier época); pregúntate si sabes escribir correctamente español; pregúntate también si puedes leer con suficiencia inglés, francés, alemán e italiano; y pregúntate asimismo si estás capacitada para exponer en público, cumpliendo con los

\footnotetext{
${ }^{1}$ Ramírez de Verger 2013.
} 
objetivos clásicos de docere, persuadere y conmovere. Si en los próximos cuatro o cinco años planificas tu trabajo (busca un syllabus adecuado en alguna Universidad anglosajona de prestigio; por ejemplo, 'Yale Undergraduate Reading List ${ }^{2}$ ), habrás conseguido una base sólida para emprender una carrera profesional solvente. Puedes alcanzarlo con un trabajo diario y disciplinado sin excusas que te desvíen de lo esencial: los textos y su interpretación sin especulaciones. Por supuesto, podrás al mismo tiempo acceder a un Máster y/o un trabajo remunerado. ¿Que no hay tiempo para tanto? Claro que sí lo hay en días de veinticuatro horas y en años de 365 días: organización y trabajo diario es la receta que no falla. Que correr una maratón no se consigue con un entrenamiento de un mes ni un buen médico se forma en un año. Lo que te estoy proponiendo es muy parecido a los MIR de Medicina, pero cuídate de no caer en las redes de los 'gurús' de Educación, donde se vende más la forma (teoría) que el fondo (contenido). Te voy a recordar el cuento homérico de las Sirenas, porque hora es ya de entrar en algún texto.

La maga Circe avisa a Ulises de un peligro que se le avecinaba: el canto de las Sirenas. Lo cuenta Homero en la mejor novela de aventuras que jamás se haya escrito, la Odisea. He aquí las palabras de Circe (Od. 12.37-58):

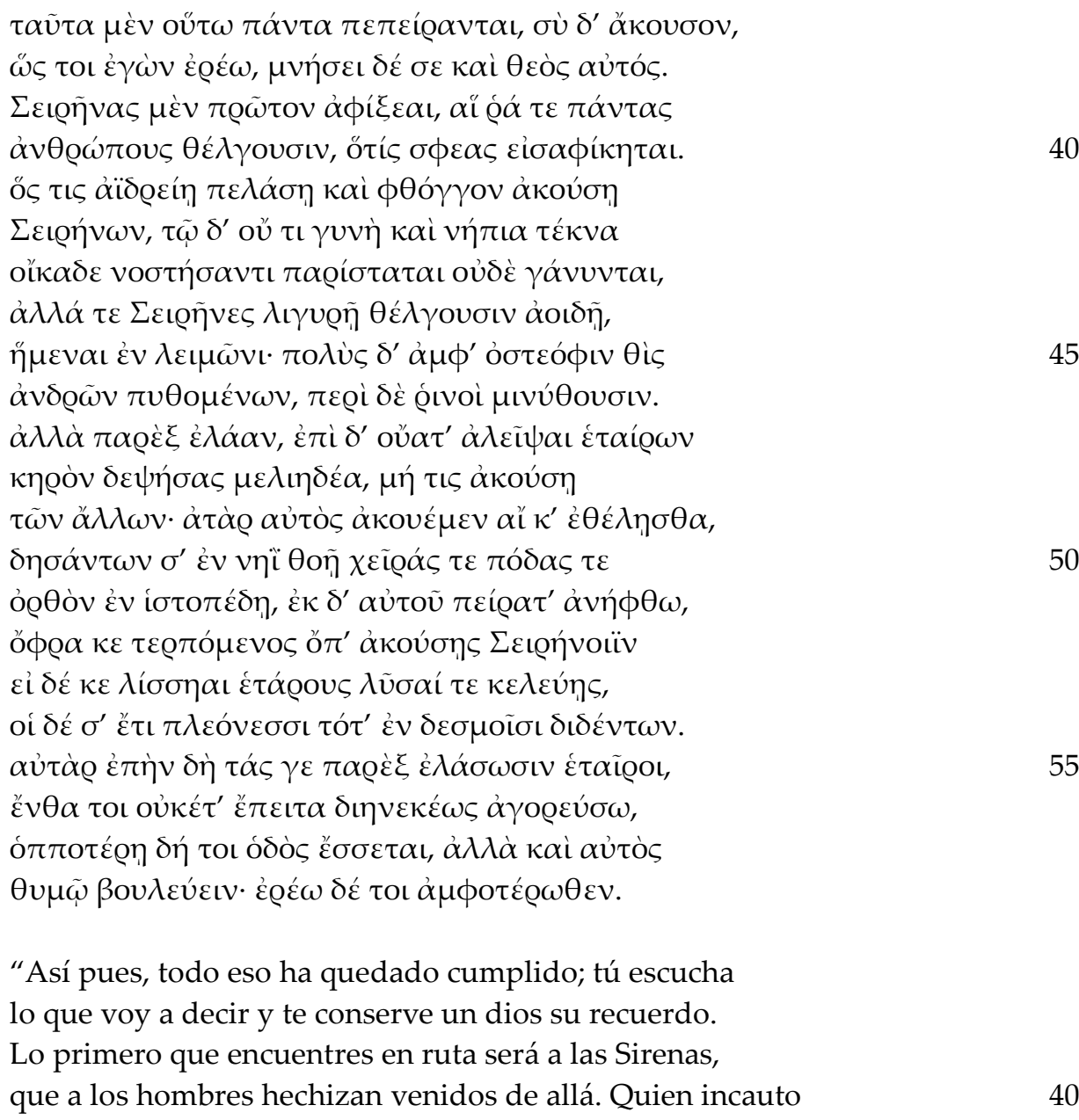

${ }^{2}<$ https://classics.yale.edu/undergraduate/reading-list> [consulta: 1 octubre 2019]. 
se les llega y escucha su voz, nunca más de regreso el país de sus padres verá ni a la esposa querida ni a los tiernos hijuelos que en torno le alegren el alma.

Con su aguda canción las Sirenas lo atraen y lo dejan para siempre en sus prados; la playa está llena de huesos

y de cuerpos marchitos con piel agotada. Tú cruza

sin pararte y obtura con masa de cera melosa el oído de los tuyos: no escuche ninguno aquel canto; sólo tú lo podrás escuchar si así quieres, mas antes han de atarte de manos y pies en la nave ligera.

Que te fijen erguido con cuerdas al palo: en tal guisa gozarás cuando dejen oír su canción las Sirenas.

Y si imploras por caso a los tuyos o mandas te suelten, te atarán cada vez con más lazos. Al cabo tus hombres lograrán rebasar con la nave la playa en que viven esas magas. No puedo decirte de fijo qué rumbo te conviene seguir después de ello. Tú mismo, pensando, lo tendrás que escoger entre dos que se ofrecen: ..."3

\section{A raíz de esta lectura le recordaba estas reflexiones mías de 2013:}

Se usa la expresión "canto de sirenas" para prevenir del peligro de dejarse seducir por falsas promesas o propuestas ilusorias, que en el fondo se quedan en la nada. En mi caso, lo voy a aplicar a la educación.

[...] Nunca, nunca se ha invertido más en educación desde primaria hasta la Universidad como en las cuatro últimas décadas en España en comparación con el subdesarrollo educativo de los años cincuenta y sesenta del siglo pasado en plena dictadura franquista. [...] Miremos nuestras guarderías, colegios de primaria, institutos o [la misma] Universidad. Contemplemos el material didáctico, las infraestructuras, los cursos, los cursillos, la inacabable burocracia. Todo muy bonito y, si se pudiera, pediríamos más cantos de sirena en la educación. Pero la realidad, cruda y dura, es que nuestros alumnos cursan 12 años de inglés y no saben inglés, cursan 12 años de lengua española y no saben escribir con corrección, cursan 12 años de matemáticas y no saben hacer una regla de tres o resolver una sencilla ecuación. Todos, sin saberlo y sin sentirlo, hemos caído en la trampa de lo moderno y lo posmoderno en la educación, de la tecnología punta y de las últimas y novísimas teorías sobre cómo hay que enseñar, incluso sin saber lo que se enseña. Sí, son cantos de sirena que se quedan en una envoltura de oropel, pero que desprecian el maná de los fundamentos: los contenidos, no las formas, que no se puede enseñar a dividir sin saber dividir ni literatura sin haber leído las mejores obras de los mejores escritores del pasado y del presente. Los cantos de sirena de los autollamados "expertos" han dejado en la playa los huesos de miles de profesores que pierden el tiempo en lo formal y olvidan lo fundamental: la transmisión de conocimientos. En más de 40 años de enseñanza, la profesión más completa y extraordinaria que existe en el mundo, he aprendido que pocas cosas hay que enseñar, además de hablar, leer, escribir y calcular en todos los niveles, claro está. Lo demás son cantos de sirena que nos alejan de lo esencial: inculcar en las aulas la cultura del esfuerzo y del conocimiento sin tapujos y sin distracciones teóricas y formales. ${ }^{4}$

${ }^{3}$ Trad. de J. M. Pabón.

${ }^{4}$ Ramírez de Verger 2013: 9-11. 
Te voy a recordar, le insistía, algunos principios. Entiendo la Filología como la ciencia que se centra en el lenguaje y los textos sin especulaciones. La Filología no entiende de modas efímeras que no duran más de una generación, ni mucho menos de aproximaciones pedantes. Una cosa es dedicarse a problemas lingüísticos y gramaticales que plantean los textos y otra, muy diferente, elaborar teorías especulativas con el simple cambio de la nomenclatura. Desconfía de los estudios que empiezan con una teoría y todo lo ajustan a ella. Hay que empezar por los textos y, después, interpretarlos. La tendencia actual es depender de un sistema, de una teoría que pretende investirse de una autoridad que durará unos pocos años. ¿Quién hace caso ya del estructuralismo y otros -ismos que en el mundo han sido? Si necesitas solventar un problema de uso sintáctico, ¿dónde podrías encontrar una posible solución? ¿En la sintaxis especulativa de H. Pinkster (1990; 2015) o en la clásica de A. Szantyr (1965), basada en textos reales de autores reales? ¿No has oído hablar del complemento 'cognado' y otros despropósitos parecidos? Como si no estuviera meridianamente claro cómo se llama el acusativo en vitam vivere o currere cursus. Pues un acusativo interno 'de figura etimológica', dicho sea en cristiano de toda la vida. ¿No es mejor dedicarse a definir el sentido exacto de una palabra en un contexto dado? Me quedo perplejo ante lo que se da en llamar "el complemento de régimen", que vienen a sustituir, por regla general, a los complementos circunstanciales, también llamados hoy "modificadores adjuntos a los verbos". Menos mal que en la Nueva gramática de la lengua española se llega a decir que "este aspecto de la relación entre el léxico y la sintaxis no ha recibido todavía una solución enteramente satisfactoria". ${ }^{5}$ ¿Y qué decir del concepto "foco"? ¿Cómo que no te llamé? Te llamé ayer. Se ha confundido un orden de palabras diferente del normal por énfasis con una nueva terminología, aparentemente brillante, pero inane. Pongo otro ejemplo. Un libro de texto de Lengua castellana y Literatura para primero de Bachillerato consta de 332 páginas y contiene toda la gramática castellana (i?) y la literatura española desde sus orígenes hasta Cervantes, además de capítulos sobre Lexicografía, Semántica, Ortografía y muchas materias más. $\mathrm{Y}$ todo se presenta muy teórico $\mathrm{y}$, a veces, incomprensible para una mente normal. Leo, por ejemplo, en la página 28 el siguiente párrafo sobre "Las implicaturas conversacionales":

Las implicaturas son las inferencias que el receptor realiza basándose tanto en el contenido de lo que se dice como en lo que asume, en función del principio de cooperación que toda interacción comunicativa debe cumplir.

Todo ese galimatías para referirse a algo tan sencillo como el contexto en la comunicación. Para entender algo de Lengua habrá que acudir a la monografía de Álex Grijelmo (2006), La gramática descomplicada. La ciencia es o debe ser sencilla, clara y directa. Y esto es lo que esperan nuestros alumnos. Y, además

\footnotetext{
${ }^{5}$ Real Academia Española 2010: 687.
} 
de saberes diferenciados, como filología, historia, matemáticas, física, ingeniería, medicina, bellas artes y otros, la Universidad debe culminar la formación de los alumnos en herramientas transversales y obligatorias en todos los Grados, como la lengua española oral y escrita o el inglés escrito y hablado y una informática avanzada.

En resumen, estimada amiga, se ha pasado de la pedagogía antigua cuartelaria a la nueva pedagogía de una escuela a donde se va a hacer actividades, no a trabajar y a estudiar, como se ha expresado la profesora sueca Inger Enkvist. ${ }^{6}$ El profesor no debe ser un psicólogo o un trabajador social o un gestor cultural. La misión de la escuela es la transmisión de conocimientos a través de la palabra oral o escrita. Y la obligación de los alumnos es aprender con trabajo, esfuerzo y, por qué no, con cierto placer.

La verdad es que no sé por qué extrañas razones te envío esta misiva sine ira et studio sobre el pasado, el presente y el futuro de la Filología Clásica. Será porque friso ya los setenta años de edad y he dedicado más de cuarenta y cinco años a la profesión de filólogo clásico con unas pocas luces y muchas sombras. Ahora bien, nadie me quitará la felicidad que he sentido en ella y la que espero seguir sintiendo durante los años que las Parcas tengan a bien concederme.

Por otra parte, quisiera prevenirte de los que en esta sociedad de capitalismo salvaje nos espetan un día sí y otro también con la pregunta sibilina de “¿para qué sirve la Filología?” No es nuevo. También el padre de Ovidio le preguntó aquello de studium quid inutile temptas? (trist. 4.10.21). ¿Para qué sirve la música, para qué el deporte, para qué la religión, para qué la política, para qué el amor, para qué, para qué...? Para alimentar el espíritu humano, para soñar, para vivir bien la vida, para, para, para... disfrutar de una obra literaria, de un discurso bien elaborado, de un movimiento sinfónico arrebatador, de una obra de arte bien explicada, para, en fin, disfrutar de la vida. Y no se olvide que "aprender para nada" es en el fondo muy rentable para la vida.

Te voy a contar lo que me sucedió no hace mucho tiempo, para que veas cómo un filólogo puede ayudar incluso a la interpretación de una pintura universal. Estuve el pasado 18 de septiembre en el Museo del Prado y me detuve largo tiempo en la sala 15A contemplando el célebre cuadro de Las hilanderas de Diego Rodríguez de Silva y Velázquez (1599-1660). Me fijé tanto en el conjunto como en los detalles (fig. 1). Cuando volví a casa, me decidí a actuar de filólogo y, tras algunas pesquisas, estas fueron mis reflexiones.

\section{DESCRIPCIÓN A PRIMERA VISTA}

El cuadro sería el reflejo costumbrista de una escena cotidiana de un taller de tapicería. Presenta dos planos. En el más cercano a nosotros una anciana y una joven se afanan en la labor de hilatura asistidas por tres doncellas que les

${ }^{6}$ El País, 24/07/2018. 
ayudan en su trabajo. En el más lejano tres damas contemplan un tapiz, difuminado en el fondo, con dos genios y un toro con una doncella en sus lomos. En el centro aparece una figura con yelmo que se dirige amenazadoramente, al parecer, contra una doncella asustada. Todavía se escribe en la leyenda explicativa del cuadro "esconder la disputa entre Palas y Aracne en el fondo de Las hilanderas, cuyo primer término está dominado por una escena aparentemente costumbrista".

\section{INDAGACIONES}

En el inventario de bienes de don Pedro de Arce (1664) se encuentra el título del cuadro: Fábula de Aracne. También sabemos que Velázquez conocía los cuadros de Tiziano y Rubens El rapto de Europa. No es difícil deducir que Velázquez había leído las Metamorfosis de Ovidio, seguramente en una traducción al español, fuera la de Jorge de Bustamante y Ludovico Dolce (1561) o la de María de Quiñones (1645). Dichas traducciones estarían basadas en buenas ediciones del original latino, fuera la de Andreas Naugerius (1516) o alguna edición Gryphiana (por ejemplo la de 1565).

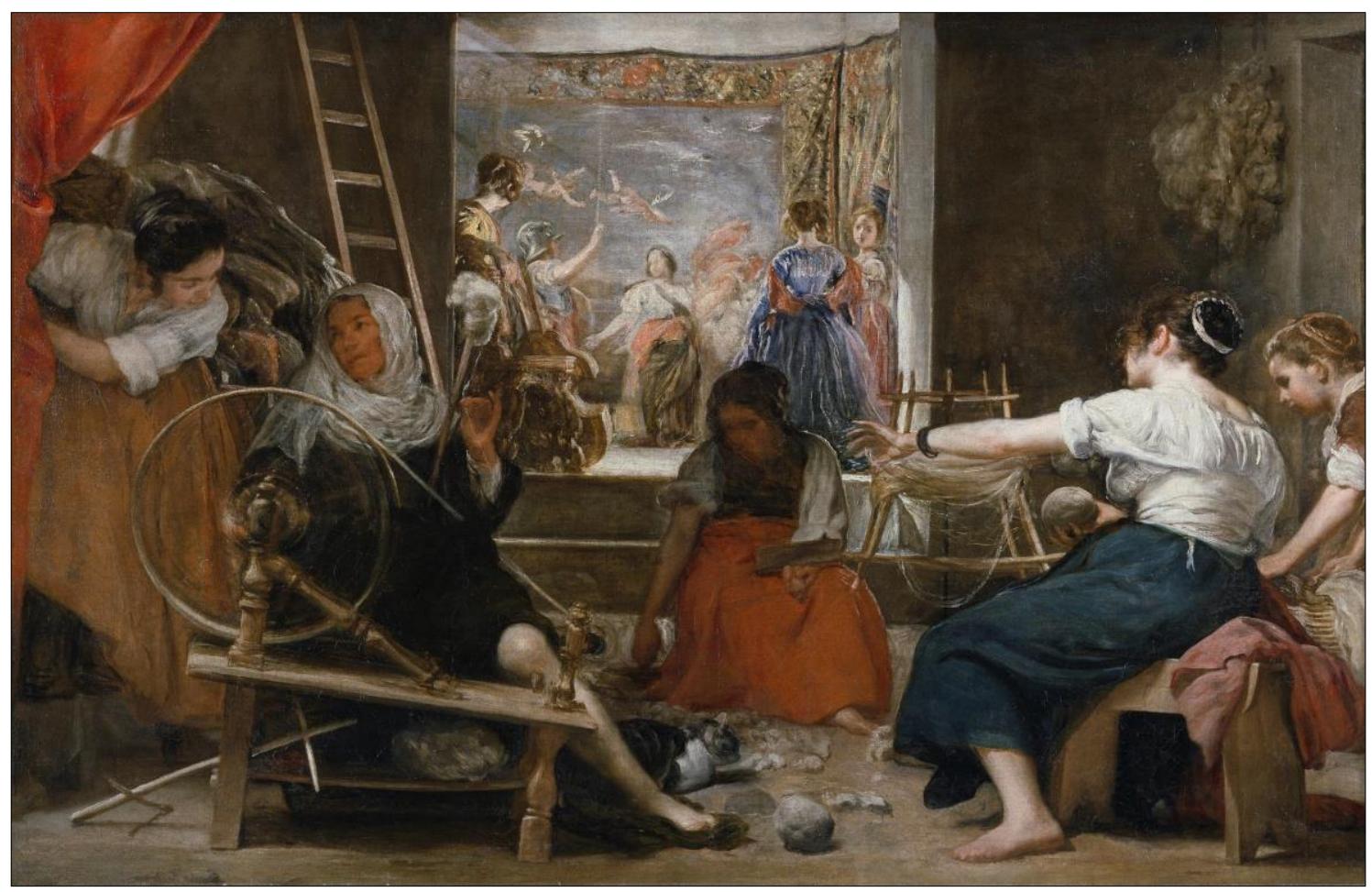

Fig. 1. Diego Rodríguez de Silva y Velázquez (1599-1660): Las hilanderas o La fábula de Aracne (óleo sobre lienzo, 1655-1660, 220 x 289 cm).

\section{LA FUENTE INSPIRADORA}

Lo cierto es que Velázquez debió de haber leído la fábula ovidiana de Aracne (met. 6.1-145), de la que selecciono algunos pasajes. 
Quod tamen ipsa negat tantaque offensa magistra 'certet' ait 'mecum: nihil est quod victa recusem'.

Pallas anum simulat falsosque in tempora canos

addit et infirmos baculo quoque sustinet artus.

Esto, sin embargo, ella lo niega y ofendida por tan gran maestra “¡compita”, dice, "conmigo!: no tengo motivos para negarme como

[una vencida". 25

Palas toma la figura de una anciana, falsas canas a sus sienes añade y sostiene también con un báculo sus débiles miembros.

Haud mora: constituunt diversis partibus ambae et gracili geminas intendunt stamine telas. tela iugo vincta est, stamen secernit harundo, inseritur medium radiis subtemen acutis, quod digiti expediunt, atque inter stamina ductum percusso paviunt insecti pectine dentes. utraque festinant cinctaeque ad pectora vestes bracchia docta movent, studio fallente laborem.

Sin demora colocan las dos en lugares distintos y tensan los telares gemelos con fina urdimbre. El telar está sujeto por el rodillo, el peine separa la urdimbre, puntiagudas lanzaderas insertan entre ella la trama, trama que desenrollan los dedos y a la que, introducida entre la urdimbre, apisonan los serrados dientes con un golpe del peine. Las dos se dan prisa y con los vestidos recogidos hasta el pecho mueven con maña los brazos engañando la fatiga con su esfuerzo.

Maeonis elusam designat imagine tauri Europen: verum taurum, freta vera putares; ipsa videbatur terras spectare relictas et comites clamare suas tactumque vereri assilientis aquae timidasque reducere plantas.

La Meónide dibuja a Europa engañada por la figura de un toro: pensarías que el toro era real y real el mar. Europa parecía que miraba a la tierra que había dejado detrás, que gritaba a sus compañeras, que temía el contacto del agua que saltaba junto a ella y que encogía sus tímidos pies.

Non illud Pallas, non illud carpere Livor possit opus. doluit successu flava virago

et rupit pictas, caelestia crimina, vestes; utque Cytoriaco radium de monte tenebat, ter quater Idmoniae frontem percussit Arachnes. non tulit infelix laqueoque animosa ligavit guttura; pendentem Pallas miserata levavit atque ita 'vive quidem, pende tamen, improba' dixit, 'lexque eadem poenae, ne sis secura futuri, dicta tuo generi serisque nepotibus esto!' 
post ea discedens sucis Hecateïdos herbae

sparsit, et extemplo tristi medicamine tactae

140

defluxere comae, cum quis et naris et aures,

fitque caput minimum, toto quoque corpore parva est;

in latere exiles digiti pro cruribus haerent,

cetera venter habet, de quo tamen illa remittit

stamen et antiquas exercet aranea telas.

No Palas, no la Envidia podrían criticar aquella obra.

Se dolió del éxito la rubia doncella

y rompió el lienzo bordado, los crímenes de los celestiales;

y con la lanzadera que tenía de madera del Citoro,

tres, cuatro veces a la Idmonia en la frente golpeó Aracne.

No lo soportó la desgraciada y con un lazo, orgullosa, se ató

la garganta; al verla colgada Palas, compadecida, la levantó

y le dijo así: "Vive pues, pero colgada, malvada,

y el mismo castigo, para que no estés despreocupada en el futuro,

sea dictado para tu linaje y tus remotos descendientes".

Después de esto, se apartó y la roció con los jugos de la hierba

de Hécate $y$, al instante, tocados por tan siniestra poción

se evaporaron sus cabellos y con ellos la nariz y las orejas,

la cabeza se reduce al mínimo y también todo su cuerpo se hace pequeño;

en el costado finos dedos en lugar de piernas le salen,

lo demás lo ocupa el vientre, del que con todo ella produce

un hilo y trabaja como araña las telas de siempre.

145

\section{DESCRIPCIÓN A SEGUNDA VISTA}

El cuadro se compone, como dije más arriba, de dos escenarios: las hilanderas que, en un primer plano, se afanan en su trabajo de hilatura en torno a dos figuras y, en un segundo plano, las damas que contemplan un hermoso tapiz al fondo.

En la primera escena aparecen dos figuras principales, una anciana y una joven, y tres secundarias, unas jóvenes asistentes. Una gata (¿Ártemis?) añade un toque hogareño a la escena. La anciana representa a la diosa Palas bajo esa apariencia y la joven de espaldas es Aracne.

De la primera escena se asciende a un segundo escenario al fondo por unas gradas. A la izquierda y apoyada en una silla se encuentra una 'viola da gamba', antecedente del actual violonchelo (la música contra el veneno de la tarántula/araña). En los extremos de este escenario aparecen tres doncellas (Ninfas), ataviadas según la época, una a la izquierda y dos a la derecha, quienes muestran su admiración por el trabajo de Aracne. A continuación, y en el centro de la escena, se encuentra Palas con el casco y escudo amonestando a una asustadiza Aracne a la izquierda. Por fin, al fondo se divisa de manera difuminada la fábula del rapto de Europa (los precedentes son El rapto de Europa 
de Tiziano de 1560-1562 y la copia de Rubens de 1628 o 1629, expuesto en la misma sala de Velázquez) y en el aire dos genios o amorcillos lo contemplan. ${ }^{7}$

Lo que te quiero transmitir, estimada amiga, es muy simple. ${ }^{8}$ Primero, dótate de una sólida base filológica (textos originales y buenos comentarios filológicos); después, enseña lo útil con agrado, como nos enseñó Horacio (ars 344: lectorem delectando pariterque monendo), aunque nadie nos librará de la gramática y del léxico, y deja poco a poco la semilla de los grandes textos literarios a través de lecturas en clase: por ejemplo, la escena de despedida de Héctor (Il. 6.369-503) y el diálogo de Aquiles con Príamo (Il. 24.469-658) de Homero; la Antígona de Sófocles; el discurso de Pericles de Tucídides (2.35-46) y el diálogo de los melios (5.85-113) del mismo autor; la Apología de Sócrates de Platón; los Epigramas de Calímaco; el epilio de Tetis y Peleo de Catulo (64); el discurso de Critognato de César (Gall. 7.77); las Bucólicas y la muerte de Turno de Virgilio (Aen. 12.919-52); algunas odas de Horacio (por ejemplo, carm. 2.16 y 3.25); la Fedra de Séneca; algunos epigramas de Marcial; el cuento de Cupido y Psique (Apuleyo, met. 4.28-6.24) y otras muchas lecturas que a ti te hayan enseñado y que te hayan conmovido.

Si piensas dedicarte no sólo a la docencia, sino también a la investigación, procura hacer un TFM puramente filológico, por ejemplo, la colación de un manuscrito: ¡hay tantos sin leer! Y, cuando te lances a la elaboración de una tesis doctoral, sigue en los textos y lánzate a un comentario de alguna obra clásica: ¡queda tanto por hacer!

$\mathrm{Y}$, cuando alguien persista en seducirte con cantos de sirenas de teorías especulativas en docencia y con pérdidas de tiempo en investigación, recuerda aquella poesía de William Butler Yeats (Irlanda, 1865-1939), publicada en 1919.

\author{
The scholars \\ Bald heads forgetful of their sins, \\ Old, learned, respectable bald heads \\ Edit and annotate the lines \\ That young men, tossing on their beds, \\ Rhymed out in love's despair \\ To flatter beauty's ignorant ear.
}

\footnotetext{
${ }^{7}$ Cf. Angulo 2010.

8 No olvides tampoco el decálogo del filólogo alemán K. Lehrs, quien en 1873 elaboró unos diez mandamientos que se debían aplicar los filólogos clásicos. Tales diez mandamientos fueron traducidos del alemán al inglés por W. M. Calder III (1980-81). He aquí su traducción española: 1. No repetirás como un papagayo; 2 . No robarás; 3 . No te inclinarás ante los manuscritos; 4 . No tomarás el nombre de Método en vano; 5 . Aprenderás a leer; 6 . No picarás en las raíces del sánscrito y rechazarás mi maná; 7 . Aprenderás a distinguir las inteligencias; 8 . No creerás que Minerva es una pura invención: ha sido dispuesta para tu sabiduría; 9. No creerás que diez malas razones equivalen a una buena; 10 . No creerás lo que unos pocos paganos han dicho: "El agua es lo mejor".
} 
All shuffle there; all cough in ink;

All wear the carpet with their shoes;

All think what other people think;

All know the man their neighbour knows.

Lord, what would they say

Did their Catullus walk that way?

Los eruditos

Cabezas calvas, olvidadas de sus pecados,

viejas, eruditas, respetables cabezas calvas,

editan y anotan los versos

que jóvenes, agitándose en sus lechos,

rimaron en sus desesperaciones de amor

para lisonjear al oído ignorante de la belleza.

Todos se arrastran por allí, todos tosen sobre la tinta,

todos gastan la alfombra con sus zapatos,

todos piensan lo que otros piensan,

todos conocen al que sus vecinos conocen.

¡Señor! ¿qué podrían los eruditos decir:

ese es el camino que su Catulo quiso seguir?

Ya basta de persuasiones from the bottom of my heart. Séate suficiente, carissima amica, seguir este lema: labora et fruere.

Vale.

\section{BIBLIOGRAFÍA}

ANGUlo, D. (2010), “Cuadros mitológicos de Velázquez: 'Las hilanderas'”, en La mitología en el arte español: del Renacimiento a Velázquez, Madrid, Real Academia de la Historia, 193-213 (= "Las Hilanderas", Archivo Español de Arte, 21, 1948, 1-19).

CALDER III, W. M. (1980-1981), “Karl Lehrs' Ten Commandments for Classical Philologists", The Classical World, 74.4, 227-228.

GRIJELMO, A. (2006), La gramática descomplicada, Madrid, Taurus.

PINKSTER, H. (1990), Latin Syntax and Semantics, Londres / Nueva York, Routledge (trad. de Torrego, E. y de la Villa, J., Sintaxis y semántica del latín, Madrid, Ediciones Clásicas, 1995).

PINKSTER, H. (2015), The Oxford Latin Syntax, vol. I: The Simple Clause, Oxford, Oxford University Press.

RAMírez DE VERGER, A. (2013), Cuentos de un filólogo (la palabra y los textos). Lección inaugural: curso académico 2013-2014, Huelva, Universidad de Huelva.

Real ACADEMia EsPañola (2010), Nueva gramática de la lengua española: Manual, Madrid, Espasa Libros.

SZANTYR, A. (1965), Lateinische Syntax und Stilistik, Múnich, Beck. 